\title{
Effect of Educational Program on Women's Awareness and their health status regarding antenatal Exercises
}

\author{
Hend Shabaan Refaey1; Ekbal Abd El Rehem Emam 2; Essa Mahmoud Mohamed 3 Amany Hassan Abd Elrahim
}

1. B.Sc. Nursing Faculty of Nursing-Minia University;

2. Professor of Woman Health and Obstetric Nursing, Faculty of nursing - Minia University

3. Assistant Professor of Obstetrics and Gynecology Medicine, Faculty of Medicine -Minia University

4. Lecturer of Woman Health and Obstetric Nursing, Faculty of Medicine -Minia University

\begin{abstract}
Background: Exercise during pregnancy is generally beneficial and can strengthen muscles, reduce backache and stress, and provide a feeling of well-being Aim of the study: This study aim was to evaluate the effect of educational program on woman's awareness and their health status regarding antenatal exercises. Research design: Quasi experimental research design (one group pre- test, post-test)was utilized to fulfill the aim of this study Setting: This study was conducted at antenatal out-patient clinic at Minia University Hospital for Obstetric \&Pediatric (MUHOP) hospital Sampling: convenient sample includes 75 pregnant women in their second trimester. Tools of data collection included: tools 1: Interviewing sheet, 2: Awareness assessment tool (pre/post educational program, 3: An observational checklist, 4: Brief Short Form Health Survey (SF-19) 1.0 Questionnaire items. Results: regarding pregnant women awareness, near to half of them their opinion about their health was fair pre educational program compared with minority of them post-test program, and improve physical function of them post educational program than pretest program regarding more three vigorous and moderate activities, lifting or carrying home purchases, bending, kneeling, standing, and walking long distances with highly statistically significance differences $\mathrm{P}-$ value $\leq$ 0.0001 respectively Conclusion: None of the pregnant woman had pre-educational program awareness compared to post-education program, as it was increased and total Short form health mean scores of the pregnant woman regarding antenatal exercise was increased post educational program than pre educational program (68.1 \pm 13.4$)$ and (54.5 \pm 12.7) respectively), Recommendation: identify the most effective specific types of guidance and motivation in the (or maintaining) exercise in pregnant women.
\end{abstract}

Keywords: Antenatal Exercises, Educational Program, Women's Awareness

\section{Introduction}

Exercise during pregnancy is generally beneficial and can strengthen muscles, reduce backache and stress, and provide a feeling of well-being. The amount and type of exercise recommended depend on the physical condition of the woman and the stage of pregnancy and relaxation exercises use during the day and before bed (Murray, et al., 2019).

Teach women who have no medical or obstetric complications to exercise in moderation for at least 20 to 30 minutes or more on most if not all days of the week (ACOG, 2015; Beckmann et al., 2014). Recreational sports can be continued if no risk of falling or abdominal trauma is present. Joint and ligament laxity and lumbar lordosis increase the risk of injury, especially in the third trimester. Contact sports and exercise with a high risk for falling such as rock climbing or skiing should be avoided. Exercise in the supine position should be discontinued after the first trimester to avoid supine hypotensive syndrome.

Walking is an ideal exercise because it stimulates muscular activity, gently increases respiratory and cardiovascular effort, and does not result in fatigue or strain. Swimming and water exercises are excellent during pregnancy because the buoyancy of the water helps prevent injuries. Riding a stationary bike and yoga are also helpful. Exercise classes especially for pregnant women are often available and offer companionship with other women having similar experiences. Instruct the woman not to begin strenuous exercise programs or intensify training during pregnancy. Those who have been exercising strenuously before pregnancy should consult the health care provider but may be able to continue (Frontera et al., 2018).

$P$ a g e $\mid 48$
As pregnancy progresses, the exercise program may need modification because the change in the woman's center of gravity makes her more prone to falls. Therefore, an activity may be safe in the first trimester but not in the third trimester. Exercise should be tailored to the way the woman feels to avoid becoming overly fatigued. Generally, if a woman cannot carry on a conversation while exercising, she is doing too much. The woman should stop exercising and seek medical advice if she has chest pain, dizziness, headache, vaginal bleeding, decreased fetal movement, or signs of labor while exercising (Linnard-Palmer, et al., 2016).

Nurses need to encourage pregnant women to perform moderate exercise. Women who exercise more or are athletes may need to change their diet to fulfil increased nutritional needs. Extra calories could be required to recover energy in exercise. Serving fruit, yoghurt, or pasta before and after exercise may suffice. Additional water should be taken before and after exercise. (Leifer, 2018).

Nurses play an important role in encouraging the effects of physical activity and fitness, educating women during breastfeeding on a healthy and safe diet, and directing them to prenatal exercise (Van Poppel, et al., 2018). With the growing amount of scientific data on the beneficial benefits of maternal physical exercise, in pregnant women, writers from various countries note their inadequate degree. There are a few research on the extent of knowledge of pregnant women and their practice of prenatal physical activity (Szumilewicz, et al., 2019).

( 


\section{Significance of the study:}

Antenatal exercises have a great benefit for pregnant women as it help to improve nausea, better ability to cope with labor and childbirth, enhanced psychological well-being, self-image and confidence. Decrease incidence of post-partum blues, improved sleep patterns, body awareness and help in quick post-natal recovery (Stephenson, 2014).

Moderate, mild exercise is helpful during regular pregnancy, but intensive exercise can be avoided. The nurse can direct the patient on exercise during pregnancy based on the assumption that the maternal circulatory system is the fetus's lifeline, and any change will affect the fetus' development and survival. Maternal cardiac status and fetoplacental reserve should be the basis for assessing exercise levels during all pregnancy trimesters. Present diet and wellbeing lifestyles mandate the provision of workout knowledge during breastfeeding in maternal education services. Activities to avoid include skydiving, horseback riding, skiing, and scuba diving (ACOG, 2016).

\section{Aim of the Study \\ This study aims to:}

Evaluate the effect of educational program on woman's awareness and their health status regarding antenatal exercises.

Research Hypothesis: Utilization of educational program will be effective in increasing women's awareness regarding antenatal exercises also improves their health status.

\section{Method Research Design \\ Quasi experimental research design was utilized to fulfill the aim of the study}

Sample A convenient sample includes 75 pregnant women in 2nd trimester, Read and write and healthy women

\section{Setting}

This study was conducted at the antenatal outpatient clinic at Minia University Hospital for Obstetric \&Pediatric (MUHOP) hospital

\section{Tools of Data Collection:}

Tools of data collection were developed by the researcher after an extensive review of the literature and similar studies conducted elsewhere. After that the developed questionnaire are revised by 5 panels of obstetrical and gynecological experts in nursing staffs, a structured interview questionnaire was developed. The data collection tool consisted of four tools:

\section{The first tool: Interviewing sheet:}

A Self-administrative questionnaire was designed to collect data related to socio-demographic characteristics of the woman such as (age, marital status, residences, educational level, and income). Also, it contains Past obstetric history as No. of gravidity, No. of parity and source of women knowledge in addition to mother telephone no.

\section{The second tool:}

Awareness assessment tool (pre/post educational program): It is a Self-Administered questionnaire that was developed by the researcher after revising relevant literature. Total number of the question were 31 questions which included questions related to different types of exercise in pregnancy (9), benefits of exercise in pregnancy (12), and contraindication of exercise in pregnancy (10)

\section{Scoring System:}

The woman's answers related to awareness were scored and the total score calculated. According to the answers of the woman's responses, it was evaluated using the model key answer sheet which prepared previously by the researcher. Women's scoring of awareness regarding antenatal exercises was classified as follows: Each correct answer was given a score of 'one' and wrong answer a score of 'zero' respectively. For each area of awareness, the scores of the items were summed-up and the total divided by the number of the items, giving a mean score for each area. Poor awareness scored $(<50 \%)$; average awareness (50\%-75\%); good awareness was considered if the percent score was $75 \%$ or more.

\section{The third tool:}

An observational checklist was used to assess the application of exercise by pregnant women. It was included five types of exercised 17 practical steps as pelvic floor exercise (3 steps) (Sit on a chair with your back against the seatback), back and abdominal exercise (3 steps) (Breath naturally), abdominal breathing exercise (3 steps) (Breath in through the nose and feel the abdomen expand), lower costal breathing ( 3 steps) (Breathe through the nose and feel your chest.), and apical breathing (5 steps) (feel the upper lungs moving slightly up and down). It was filed by the researcher and was administered during and post-test after three months of the program.

\section{Scoring System:}

Application of exercise by pregnant women was classified as follows: Each correct practice was given a score of 'one' and wrong practice a score of 'zero' respectively for every step of exercises. Poor practice scored $(<50 \%)$; average practice $(50 \%-75 \%)$; the good practice was considered if the percent score was $75 \%$ or more. the observational checklist was graded as done and not done for every step of the exercise.

\section{The fourth tool:}

Short Form Health Survey (SF-36) 1.0 Questionnaire Items. is one of the most popular instruments for assessing the HRQoL that, as a standard instrument, assesses the health outcomes. This questionnaire assessed two distinct dimensions of health, physical and psychological, and each dimension is composed of four domains. The physical dimension of HRQoL assessed the domains of physical functioning (5 items) (Lifting or carrying home purchases), role limitation-physical (3 items) (limited in the kind of work or other activities)، and general health (1 item) (what would you say about your health), social functioning (2 items) (How much of the time has your pregnancy-related emotional problems interfered with your social activities), pain (2) (How much bodily pain have you had during the past 4 weeks), and energy/ fatigue/ emotional (6 items) (Have you been a very nervous person). 


\section{Scoring system}

The SF-19 consists of eight scaled scores, which were the weighted sums of the questions in their section. Each scale was directly transformed into a 0-100 scale on the assumption that each question carries equal weight, the lower the score the more disability and the higher the score the less disability i.e., a score of zero is equivalent to maximum disability and a score of 100 is equivalent to no disability.

\section{Validity and Reliability}

To establish validity, the questionnaire was piloted on a panel of 5 experts of Obstetrics and Gynecological staff, and Nursing professors who reviewed the instruments for clarity, relevance, comprehensiveness, understanding, applicability, and easiness, to establish reliability, alpha Cronbach's way to check the stability of the internal consistency of instrument were .079, .847, and .915 respectively.

Procedure The current study was achieved through three phases: Assessment phase that was included (pre-test to assess women awareness regarding benefits, types, indication, and contraindication of antenatal exercises). Implementation phase that included 1.conducting education program, and 2. Application of some types of antenatal exercises (pelvic floor exercises, back \& abdominal exercises, and breathing exercises). Evaluation phase that was included (post-test and using an observational checklist).

\section{Assessment phase(pre-test)}

During the assessment phase the researcher held the first meeting with women to introduce self and explained the nature and purpose, duration, and activities of the study. They were informed that participation in this study was voluntary and they had the right to withdraw at any time, oral approval of women to share in the study was achieved.

After obtaining the acceptance from women to participate in the current research, the researcher provided an overview and clarification about the assessment tool question then the self-administered questionnaire was distributed to each woman to assess data related to socio-demographic data and obstetric history, the questionnaire took about 15 minutes to be completed.

Then the researcher distributed the pretest questionnaire to assess women's awareness regarding antenatal exercises benefits, types, indication, and contraindication of antenatal exercises).

\section{Implementation phase (conducting education program)}

After assessing women's awareness regarding antenatal exercises benefits, types, indication, and contraindication of antenatal exercises) by awareness assessment questionnaire, the researcher collected the sample through two days per week from the beginning of the study. The study was carried out in the period from 15 July 2019 to the 15 February 2020. The researcher attended to antenatal care Department at 9:00 a.m., to 1:00 p.m.; Face to face interview.

The total sample (75) was divided into a small group. The session's numbers were around two sessions/ day for each small group. Each session lasted for around 35 to 45 minutes. During implementation of health education program, the woman in the study sample received the knowledge regarding antenatal exercises as benefits, types, indication, and contraindication of antenatal exercises) were given to the women through used face to face method to achieved the desired goal and allow women to ask, discussion and reach a high level of understanding. During these sessions, the researcher used illustrations, examples of objects, booklets, and brochures the discussion was emphasized on improving women's knowledge. An additional 15 minutes were assigned at the end of the discussion for questions and obtain the feedback to ensure that the women got maximum benefits. The entire study sample received booklet includes knowledge related to exercise.

\section{Evaluation phase (post-test)}

Three times of evaluation was done for each woman:

The first evaluation (pretest) was done before implementation of the guideline as a baseline data using the tool to assess awareness of the pregnant women. The second evaluation was conducted immediately after the educational program to detect the level of women's awareness after health education regarding antenatal exercises. The third evaluation (posttest) an observational checklist was used after three months (posttest) for final evaluation.

The effect of health education program was done through comparing between pretest and posttest that were conducted immediately and after three months

Pilot Study: A pilot study was conducted on ( 8 women) $10 \%$ of antenatal mothers at the previously mentioned setting to assess the current study tools for its clarity, validity, and time required to be applied. According to the results of the pilot, all required and necessary modifications were done and the women who were tested in the pilot study not included in the study sample

Ethical Consideration: Official permission to carry out the study obtained from women that are willing to participate in the study, after explaining the importance, aim, nature and purpose of the study, oral consent obtained from all women, all participants have the right to refuse to participate and or withdraw from the study without Any rational any time, privacy was considered during the collection of data, no health hazards were present. Participants were assured that all their data are highly confidential, anonymity was also assured through assigning a number for each woman instead of names to protect their privacy.

Statistical Design the collected data were organized, categorized, and analyzed using the statistical package of social science (SPSS) version 20 and Excel for figures. Data were presented using descriptive statistics in the form of frequencies and percentages for qualitative variables, and means and standard deviations for quantitative variables. Statistical significance was considered when $\mathrm{P}$ value $\leq 0.05$, high Statistical significance was considered when $\mathrm{P}$ value $\leq 0.001$, no Statistical significance was considered when $\mathrm{P}$ value $\geq 0.05$ fisher exact test was used to detect the relation between women knowledge based on their selected sociodemographic characteristics and the relation between women awareness and their clinical outcome. 
Minia Scientific Nursing Journal (Print - ISSN 2537-012X) (Online - ISSN 2785-9797) Vol. (8) No. (1) December 2020

\section{Results:}

Table (1): Frequency distribution of the studied pregnant woman according to their socio-demographic characteristics ( $\mathrm{n}=\mathbf{7 5}$ ).

\begin{tabular}{|l|c|c|}
\hline \multicolumn{1}{|c|}{ Personal characteristics } & No. $(\mathbf{n}=\mathbf{7 5})$ & \% \\
\hline Age $/$ years & 4 & 5.3 \\
\hline $15-<20$ & 39 & 52.0 \\
\hline $20-<25$ & 18 & 24.0 \\
\hline $25-<30$ & 10 & 13.4 \\
\hline $30-<35$ & 4 & 5.3 \\
\hline $35-<40$ & $25.1 \pm 4.9$ years \\
\hline Mean \pm SD & & \\
\hline Occupation & 56 & 74.7 \\
\hline House wives & 19 & 25.3 \\
\hline Office work & & \\
\hline Educational level & 10 & 13.3 \\
\hline Read and write & 41 & 54.7 \\
\hline Basic education & 20 & 26.7 \\
\hline University educated & 4 & 5.3 \\
\hline Post university-educated & & \\
\hline Residence & 52 & 69.3 \\
\hline Rural & 23 & 30.7 \\
\hline Urban & & \\
\hline
\end{tabular}

Table (1): shows that, $52.0 \%$ of pregnant women aged between $20-<25$ years with mean $25.1 \pm 4.9$ years. Regarding pregnant women occupations, $74.7 \%$ of them were housewives, $56.7 \%$ of them had basic education and $69.3 \%$ of them lived in a rural area.

Table (2): Frequency distribution of obstetric history of the pregnant woman $(n=75)$.

\begin{tabular}{|l|c|c|}
\hline \multicolumn{1}{|c|}{ Obstetric history } & No. $(\mathbf{n}=\mathbf{7 5}$ & \% \\
\hline Parity & & \\
\hline Nulliparous & 14 & 18.7 \\
\hline Primiparous & 61 & 81.3 \\
\hline Last parity (n= 61) & 3 & 4.9 \\
\hline One year & 58 & 95.1 \\
\hline More years & & \\
\hline Mode of delivery (n= 61) & 20 & 32.8 \\
\hline Vaginal & 41 & 67.2 \\
\hline Cesarean section & & \\
\hline Place of delivery (n= 61) & 29 & 47.5 \\
\hline MCH & 20 & 32.8 \\
\hline Private hospital & 12 & 19.7 \\
\hline Others & & \\
\hline Previous complication (n= 61) & 7 & 11.5 \\
\hline Yes & 54 & 88.5 \\
\hline No & & \\
\hline \# Sources of information & 21 & 28.0 \\
\hline Television & 21 & 28.0 \\
\hline Parents & 10 & 13.3 \\
\hline Friends & 11 & 14.7 \\
\hline Doctor & 6 & 8.0 \\
\hline Nurse & 6 & 8.0 \\
\hline Relative & & \\
\hline
\end{tabular}

\# Responses not normally exclusive

Table (2): presents that, $81.3 \%$ of pregnant women had primipara, and $95.1 \%$ of them last parity was from more than one year. Regarding mode of delivery, $67.2 \%$ of women delivered by caesarian section, $47.5 \%$ of them delivered in maternal and child health center, and $88.5 \%$ of them didn't have any previous complications. Concerning pregnant women sources of information, $28.0 \%, 28.0 \%$ of them their source was a television and their parents respectively. 
Minia Scientific Nursing Journal (Print - ISSN 2537-012X) (Online - ISSN 2785-9797) Vol. (8) No. (1) December 2020

Table (3) Relation between total pregnant women awareness levels regarding antenatal exercise on pre and post educational programs $(n=75)$.

\begin{tabular}{|c|c|c|c|c|c|c|}
\hline \multirow[t]{2}{*}{ Awareness level } & \multicolumn{2}{|c|}{ Pre } & \multicolumn{2}{|c|}{ Post } & \multirow{2}{*}{$\begin{array}{c}\text { Fisher } \\
\text { test }\end{array}$} & \multirow[t]{2}{*}{ P-value } \\
\hline & No. & $\%$ & No. & $\%$ & & \\
\hline Poor awareness & 69 & 92.0 & 0 & .0 & \multirow{3}{*}{180.672} & \multirow{3}{*}{$.0001 * *$} \\
\hline Average awareness & 6 & 8.0 & 7 & 9.3 & & \\
\hline Good awareness & 0 & .0 & 68 & 90.7 & & \\
\hline
\end{tabular}

$* *$ Highly statistical significant difference at $\leq 0.01$

Table (3): shows that $92.0 \%$ of the pregnant woman had poor awareness regarding antenatal exercise pre educational program compared with $0.0 \%$ of them post-education program, $8.0 \%$ of them had average awareness pre-educational program compared with $9.3 \%$ of them post-education program, and $0.0 \%$ of the pregnant woman had good awareness pre educational program compared with $90.7 \%$ of them post education program with highly statistically significance differences $\mathrm{P}-$ value $\leq 0.0001$.

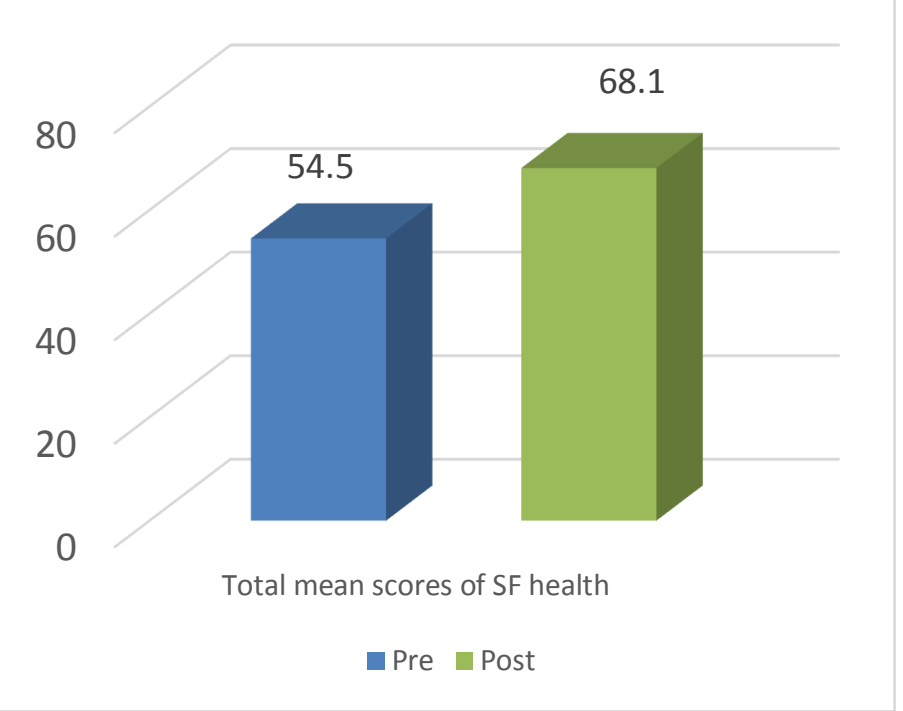

Figure (1) Frequency distribution of total Short form health mean scores of the pregnant woman regarding antenatal exercise (n= 75).

Figure (1): illustrates that total Short form health mean scores of the pregnant woman regarding antenatal exercise was higher in post educational program than pre educational program $(68.1 \pm 13.4)$ and $(54.5 \pm 12.7)$ respectively)

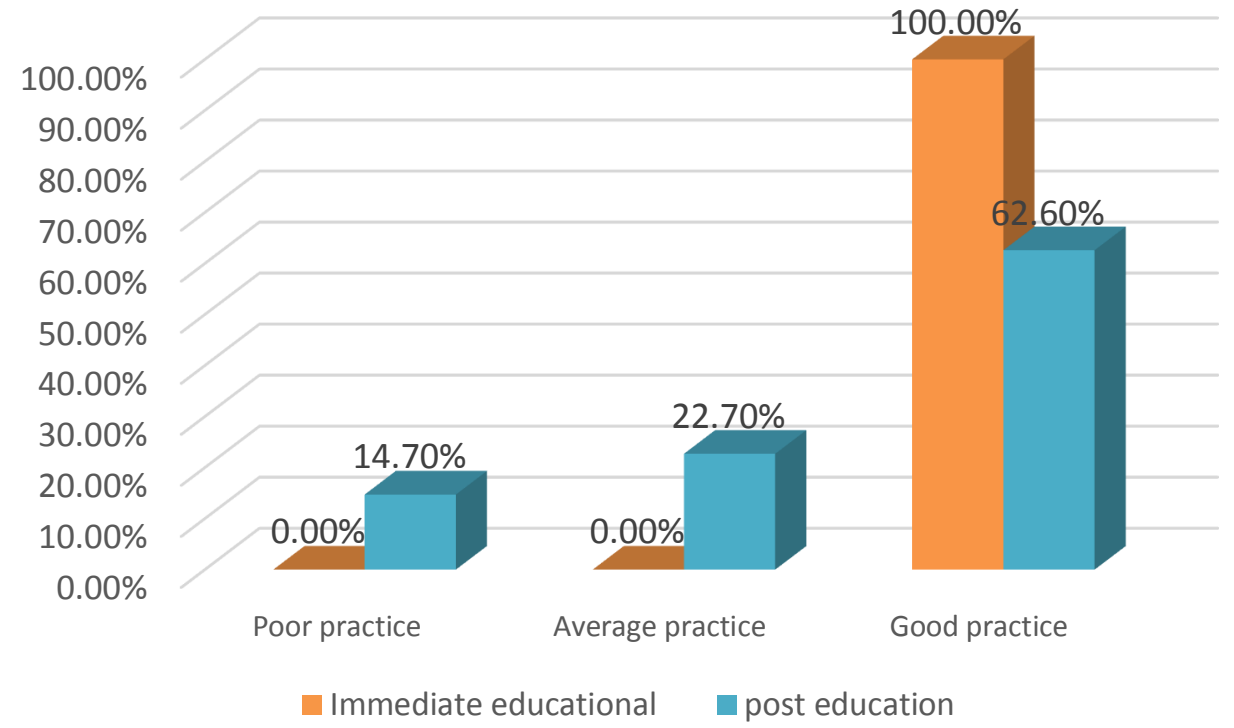

Figure 2 Frequency distribution of the pregnant woman practice levels regarding antenatal exercise $(n=75)$.

Figure (2): illustrates that none $(0.0 \%)$ of the pregnant woman had poor practice regarding antenatal exercise immediately after educational program compared with $14.7 \%$ post-education program, none $(0.0 \%)$ of the pregnant woman had average practice regarding antenatal exercise immediately educational program compared with $22.7 \%$ post-education program, and all (100.0\%) of the pregnant woman had good practice regarding antenatal exercise immediately after educational program compared with $62.6 \%$ posteducation program. 
Minia Scientific Nursing Journal (Print - ISSN 2537-012X) (Online - ISSN 2785-9797) Vol. (8) No. (1) December 2020

Table (4): Relation between socio-demographic characteristics of the woman and their awareness levels regarding antenatal exercise pre educational program $(n=75)$.

\begin{tabular}{|c|c|c|c|c|c|c|}
\hline \multirow{3}{*}{ Personal characteristics } & \multicolumn{4}{|c|}{ Pre } & \multicolumn{2}{|c|}{$\begin{array}{c}\text { Test of } \\
\text { significance }\end{array}$} \\
\hline & \multicolumn{2}{|c|}{$\begin{array}{c}\text { Poor awareness } \\
(n=69)\end{array}$} & \multicolumn{2}{|c|}{$\begin{array}{c}\text { Average } \\
\text { awareness } \\
(n=6)\end{array}$} & \multirow[t]{2}{*}{$\begin{array}{c}\text { Fisher } \\
\text { test }\end{array}$} & \multirow[t]{2}{*}{$\begin{array}{c}\text { P- } \\
\text { value }\end{array}$} \\
\hline & No. & $\%$ & No. & $\%$ & & \\
\hline \multicolumn{7}{|l|}{ Age / years } \\
\hline $15-<20$ & 4 & 5.8 & 0 & .0 & \multirow{5}{*}{5.677} & \multirow{5}{*}{.225} \\
\hline $20-<25$ & 38 & 55.1 & 1 & 16.7 & & \\
\hline $25-<30$ & 16 & 23.2 & 2 & 33.3 & & \\
\hline $30-<35$ & 8 & 11.6 & 2 & 33.3 & & \\
\hline $35-<40$ & 3 & 4.3 & 1 & 16.7 & & \\
\hline \multicolumn{7}{|l|}{ Occupation } \\
\hline House wives & 54 & 78.3 & 2 & 33.3 & \multirow[t]{2}{*}{5.890} & \multirow[t]{2}{*}{$.015^{*}$} \\
\hline Office work & 15 & 21.7 & 4 & 66.7 & & \\
\hline \multicolumn{7}{|l|}{ Educational level } \\
\hline Read and write & 10 & 14.5 & 0 & .0 & \multirow{4}{*}{2.857} & \multirow{4}{*}{.414} \\
\hline Basic education & 37 & 53.6 & 4 & 66.7 & & \\
\hline University educated & 19 & 27.5 & 1 & 16.7 & & \\
\hline Post university-educated & 3 & 4.4 & 1 & 16.7 & & \\
\hline \multicolumn{7}{|l|}{ Residence } \\
\hline Rural & 49 & 71.0 & 3 & 50.0 & \multirow[t]{2}{*}{1.146} & \multirow[t]{2}{*}{.284} \\
\hline Urban & 20 & 29.0 & 3 & 50.0 & & \\
\hline
\end{tabular}

* Statistical significant difference at $\leq 0.05$

Table (4): find that, there were no statistically significant differences between socio-demographic characteristics of the woman and their awareness levels regarding antenatal exercise pre educational program EXCEPT their occupation, 78.3\% of women had poor awareness were houses wives pre educational program with statistically significance differences P-value .015.

Table (5): Correlation matrix between total awareness, total health status, and total practice scores of the woman regarding antenatal exercise pre educational program $(n=75)$.

\begin{tabular}{|l|l|r|r|r|}
\hline \multicolumn{2}{|l}{} & $\begin{array}{r}\text { Total awareness } \\
\text { scores }\end{array}$ & $\begin{array}{c}\text { Total SF } \\
\text { scores }\end{array}$ & $\begin{array}{l}\text { Total practice } \\
\text { scores }\end{array}$ \\
\hline Total awareness scores & $\mathrm{r}$ & & & \\
\cline { 2 - 5 } & $\mathrm{P}$-value & & & \\
\hline Total SF scores & $\mathrm{r}$ & $-.098-$ & & \\
\cline { 2 - 5 } & $\mathrm{P}-$ value & .403 & & \\
\hline Total practice scores & $\mathrm{r}$ & $.288^{*}$ & $-.146-$ & \\
\cline { 2 - 5 } & $\mathrm{P}-$ value & .012 & .213 & \\
\hline
\end{tabular}

Table (5): presents that, there were no statistically significant differences between total awareness, total health status, and total practices scores of the woman regarding antenatal exercise pre educational program

\section{Discussion}

This study aim to evaluate the effect of educational program on women's awareness and their health status regarding antenatal exercises. Antenatal care is a part of the public health promotion and prevention program in most countries. Safe maternity with improved neonatal outcomes is predicated on proper antenatal health care services, regular exercise is promoted for its overall health benefits. Antenatal exercises provide many health benefits to pregnant mothers and their fetuses (Hasan et al., 2019).

Regarding the Socio-demographic characteristics of the pregnant woman, the current study showed that, more than half of pregnant women aged between $20-<25$ years with mean $25.1 \pm 4.9$ years. This result come in the line with (Prabha et al., 2019) who studied effects of antenatal exercise program and education on health related quality of life: a randomized controlled trial and reported that the mean age of the studied sample were 26.30 (3.35). this result differ with (Otaiby et al., 2013) "An Assessment of Pregnant Women Knowledge and Preferences in Saudi Arabia". Who studied and mentioned that the mean age for the sample was $28.5 \pm 6.7$ years.

Regarding pregnant women occupation, slightly less than three quarter of them were housewives, more than half of them had basic education and more than two third of them lived in the rural area. This result come inconsistent with(Prabha et al., 2019) who stated that more than half of the studied sample were undergraduate education and more than half live-in rural area. This result come in accordance with (Otaiby et al., 2013) who stated that less than two third of the studied sample were housewives, but the current study differ with the same author who stated that slightly less than half of the studied sample had a college degree or more. 
The current study come in accordance with (Sujindra et al., 2015) who studied " Knowledge, attitude, and practice of exercise during pregnancy among antenatal mothers" and reported that the majority of the study had undergone primary education and more two third were homemakers. This may be due to that the most of people in rural area not interested in women education and they have a concept that the woman is only suitable for being a housewife. Regarding obstetric history of the pregnant woman, the present study illustrated that, the most of the pregnant women had primipara and the majority of them last parity was from more than one year. This result come inconsistent with (Mbada et al., 2014) who studied knowledge and attitude of Nigerian pregnant women towards antenatal exercise: a crosssectional survey and reported that the most of the studied sample were nulliparous and (Otaiby et al., 2013) who stated that most of the sample had given birth to more than one child.

Regarding mode of delivery, more than two third of women delivered by caesarean section, less than half of them delivered in maternal and child health center and the most of them didn't had any previous complications. This result in the same line with Mobarak and Sultan, (2019) assessed " identify prevalence, indications and determinants of CS in Alexandria, Egypt" carried out in Alexandria, Egypt between July and December 2017 reported that prevalence of CS in Alexandria (2017) was $70.4 \%$.

Concerning pregnant women sources of information, the current study showed that less than one third of them their source was television and their parents respectively. This result differ with (Otaiby et al., 2013) who studied antenatal education: an assessment of pregnant women knowledge and preferences in Saudi Arabia and reported that Physicians were the preferred source of information by two third of the participants. This result come in the line with (Wijesiriwardana \& Gunawardena, 2016)" who studied Knowledge, attitudes and practices regarding antenatal exercises among pregnant mothers attending De Soyza Maternity Hospital Colombo" then, stated that the sources of information for less than half were written media and electronic media. This may be due to that the rural area dependent on traditional habits and their parent experiences

Regarding the relation between pregnant women awareness regarding their physical functioning on pre and post educational program, the current study showed that improvement of physical function of pregnant women post educational program than pre educational program about vigorous and moderate activities, lifting or carrying home purchases, bending, kneeling, standing, and walking long distances with highly statistically significance differences

This result was confirmed by (Prather et al., 2012) who studied "benefits of exercise during pregnancy" they reported that "Maternal benefits from exercise during pregnancy include improved cardiovascular function, a lower the risk of gestational diabetes in women who are obese or not obese, improved strength and lean muscle mass, improved sense of well-being, and enhanced sleep.

Regarding the relation between socio-demographic characteristics of the woman and their awareness levels regarding antenatal exercise post educational program, the present study showed that there was no statistically significance differences between socio-demographic characteristics of the woman and their awareness levels regarding antenatal exercise post educational program. This result came inconsistent with (Wijesiriwardana \& Gunawardena, 2016) who founded that doing a job during pregnancy was significantly associated with possessing a 'Good/Excellent' level of knowledge on antenatal exercises among pregnant mothers. Similarly, living in a district other than Colombo was also associated significantly with 'Good/Excellent' level of knowledge regarding antenatal exercises and being occupied was associated with a level of 'Good/excellent' knowledge regarding antenatal exercises. In addition to this Watson et al., (2015) supported this result who founded that "although age and years of practice played no role in this awareness, practitioners who focused on obstetrics and gynecology were more likely to be aware of the current guidelines, than those in general practice

Conclusion Based on the findings of the current study the following conclusions can be drawn: None of the pregnant woman had pre-educational program awareness compared to post-education program, as it was increased and total Short form health mean scores of the pregnant woman regarding antenatal exercise was increased post educational program than pre educational program $(68.1 \pm 13.4)$ and $(54.5 \pm 12.7)$ respectively).

Recommendations Physical exercise services are recommended for pregnant women and are growing in popularity gradually

- Obstetric nurses should provide educational classes for the mothers' nurses to teach exercise for pregnant women and integrate this instruction into a holistic strategy that acknowledges other health habits.

- $\quad$ Providing posters, booklets, and leaflets for mothers about the importance of prenatal exercise.

- Further work is required to identify the most effective specific types of guidance and motivation in the (or maintaining) exercise in pregnant women.

\section{References}

(1) ACOG. Air travel during pregnancy. ACOG. 2016. Accessed at http://www.acog.org/Resources-And-Publications/CommitteeOpinions/Committee-on-Obstetric-Practice/Air-Travel-DuringPregnancy in June 2017.

(2) American College of Obstetricians and Gynecologists (ACOG) (2015). Physical activity and exercise during pregnancy and the postpartum period, ACOG Committee Opinion No. 650. Online at www.acog.org.

(3) Beckmann, C. R. B., Ling, F. W, Herbert, W N. P., Laube, D. W, \& Smith, R. P. (2014). Obstetrics and gynecology (7th ed.) Philadelphia, PA: Lippincott Williams \& Wilkins.

(4) Frontera W. Herring S., Micheli L., Silver J . (2018). Medical management and rehabilitation. Saunders Elsever. 5th edition. Chapter 6: general medical problems of the athete. PP: 64- 68.

(5) Hasan, M., Zahid, S., Hafeez, S., Hashmi, Z., Mannan, H., \& Hassan, D. (2019). Knowledge and attitude of Pakistani women towards antenatal exercise: A cross-sectional survey across Lahore. JPMA. The Journal of the Pakistan Medical Association, 69(12),p 1900.

(6) Leifer G. (2018). Introduction to maternity and ppediatric nursing. 8th edition Evolve. Chapter

(7) Linnard-Palmer L. and Coats G. (2017). Safe maternity \& Pediatric Nursing care. Unit eight: deviations in pediatric health; chapter 10: Philadelphia: F.A Davis Company; 467- 468.

(8) Mbada, Ch., Adebayo, O., Adeyemi, A., Arije, O., Dada, O., Akinwande, O., Awotidebe, T., Alonge, I., (2014). "Knowledge and Attitude of Nigerian Pregnant Women towards Antenatal Exercise: A Cross-Sectional Survey", International Scholarly Research Notices, vol. 2014, Article ID 260539, PP. 8 
(9) Mobarak EI. and Sultan EA. (2019). Prevalence, Indications and Determinants of Caesarean Delivery in Alexandria, Egypt. Journal of High Institute of Public Health;49(2):125-132.

(10) Murray, Sh., McKinney E., Holub R. (2019). Foundations of maternal newborn and women's health nursing. Chapter 7: antepartum assessment, care, and education. Elsevier company. 7th edition, 141-142.

(11) Otaiby, T. A., Jradi, H., \& Bawazir, A. (2013). Antenatal Education: An Assessment of Pregnant Women Knowledge and Preferences in Saudi Arabia. J Women's Health Care, 2(139), pp2167-0420.

(12) Prabha, B. S., Vijayaraghavan, J., Maiya, A. G., Venkatesh, N., \& Sivakumar, R. (2019). Effects of Antenatal Exercise Programme and Education on Health Related Quality of Life: A Randomised Controlled Trial. Journal of Clinical \& Diagnostic Research, $13 \mathrm{p}(2)$.

(13) Prather, H., Spitznagle, T., \& Hunt, D. (2012). Benefits of exercise during pregnancy. $\mathrm{PM} \& \mathrm{R}, 4(11)$, pp845-850.

(14) Stephenson, L. O’Connor s, (2017). Obstetric and Gynecologic "Effect of physical Activity in Pregnant Women's Health Status " Vol 4, 5ed, pp.125-189, 2017.
(15) Sujindra, E., Bupathy, A., Suganya, A., \& Praveena, R. (2015) Knowledge, attitude, and practice of exercise during pregnancy among antenatal mothers. International Journal of Educational and Psychological Researches, 1(3), p234.

(16) Szumilewicz, A., Worska, A., Santos-Rocha, R., and Oviedo-Caro M. (2019). Evidence-based and practice-oriented guidelines for exercising during pregnancy. In Santos-Rocha (2019). Exercise and sporting activity during pregnancy. Springer company. E book, $157-16$.

(17) Van Poppel M, Owe K, Santos-Rocha R, Dias H. (2018). Physical activity, exercise, and health promotion for the pregnant exerciser and the pregnant athlete. In: Santos-Rocha R, editor. Exercise and sporting activity during pregnancy evidence-based guidelines. Cham: Springer; 2018.

(18) Watson, E. D., Oddie, B., \& Constantinou, D. (2015). Exercise during pregnancy: knowledge and beliefs of medical practitioners in South Africa: a survey study. BMC pregnancy and childbirth, 15(1), pp245.

(19) Wijesiriwardana, W., \& Gunawardena, N. (2016). Knowledge, attitudes and practices regarding antenatal exercises among pregnant mothers attending De Soyza Maternity Hospital Colombo. Sri Lanka Journal of Obstetrics and Gynaecology, 37p (4) 